\title{
A Novel Clustering Scheme For Heterogeneous Cognitive Radio Wireless Sensor Networks
}

Un nuevo esquema de agrupación para redes sensoras inalámbricas de radio cognitivas heterogéneas

Um novo esquema de agrupamento para redes de sensores de rádio rádio cognitivos heterogêneos

\section{Gyanendra Prasad Joshi ${ }^{1}$ Sudan Jha ${ }^{2}$}

Received: May $15^{\text {th }}, 2020$

Accepted: July $25^{\text {th }}, 2020$ Available: September $1^{\text {th }}, 2020$

How to cite this article: G. Prasad Joshi, S. Jha, "A Novel Clustering Scheme For Heterogeneous Cognitive Radio Wireless Sensor Networks," Revista Ingeniería Solidaria, vol. 16, no. 3, 2020. doi: https://doi.org/10.16925/2357-6014.2020.03.04

Artículo de investigación. https://doi.org/10.16925/2357-6014.2020.03.04

1 Department of Computer Science and Engineering, Sejong University, Neungdong-ro, Gwangjin-gu, Seoul, 05006, Republic of Korea

ORCID: https://orcid.org/0000-0002-5446-288X

E-mail: joshi@sejong.ac.kr

2 School of Computer Science and Engineering, Lovely Professional University, Panjab, India

ORCID: https://orcid.org/0000-0003-0074-2584

E-mail: sudhan.25850@lpu.co.in 


\section{Abstract}

Introduction: This article is the product of the research "Learning-based Spectrum Analysis and Prediction in Cognitive Radio Sensor Networks", developed at Sejong University in the year 2019.

Problem: Most of the clustering schemes for distributed cognitive radio-enabled wireless sensor networks consider homogeneous cognitive radio-enabled wireless sensors. Many clustering schemes for such homogeneous cognitive radio-enabled wireless sensor networks waste resources and suffer from energy inefficiency because of the unnecessary overheads.

Objective: The objective of the research is to propose a node clustering scheme that conserves energy and prolongs network lifetime.

Methodology: A heterogeneous cognitive radio-enabled wireless sensor network in which only a few nodes have a cognitive radio module and the other nodes are normal sensor nodes. Along with the hardware cost, the proposed scheme is efficient in energy consumption.

Results: We simulated the proposed scheme and compared it with the homogeneous cognitive radio-enabled wireless sensor networks. The results show that the proposed scheme is efficient in terms of energy consumption.

Conclusion: The proposed node clustering scheme performs better in terms of network energy conservation and network partition.

Originality: There are heterogeneous node clustering schemes in the literature for cooperative spectrum sensing and energy efficiency, but to the best of our knowledge, there is no study that proposes a non-cognitive radio-enabled sensor clustering for energy conservation along with cognitive radio-enabled wireless sensors.

Limitations: The deployment of the proposed special device for cognitive radio-enabled wireless sensors is complicated and requires special hardware with better battery powered cognitive sensor nodes.

Keywords: CR-WSNs, cognitive radio-enabled sensors, energy efficiency, energy conservation

\section{Resumen}

Introducción: Este artículo es el producto de la investigación "Análisis y predicción del espectro basados en el aprendizaje en redes cognitivas de sensores de radio", desarrollada en la Universidad de Sejong en el año 2019.

Problema: La mayoría de los esquemas de agrupamiento para redes de sensores inalámbricos con radio cognitivo distribuido consideran sensores inalámbricos cognitivos homogéneos con radio habilitado. Muchos esquemas de agrupamiento para tales redes de sensores inalámbricos cognitivos homogéneos habilitados para radio desperdician recursos y sufren de ineficiencia energética debido a los gastos generales innecesarios.

Objetivo: El objetivo de la investigación es proponer un esquema de agrupación de nodos que conserve la energía y prolongue la vida útil de la red.

Metodología: una red heterogénea de sensores inalámbricos cognitivos habilitados para radio en la que solo unos pocos nodos tienen un módulo de radio cognitivo y los otros nodos son nodos sensores normales. Junto con el costo del hardware, el esquema propuesto es eficiente en el consumo de energía.

Resultados: Simulamos el esquema propuesto y lo comparamos con las redes de sensores inalámbricos cognitivos homogéneos habilitados por radio. Los resultados muestran que el esquema propuesto es eficiente en términos de consumo de energía.

Conclusión: El esquema de agrupación de nodos propuesto funciona mejor en términos de conservación de energía de red y partición de red. 
Originalidad: existen esquemas de agrupación de nodos heterogéneos en la literatura para la detección cooperativa del espectro y la eficiencia energética, pero hasta donde sabemos, no existe ningún estudio que proponga una agrupación de sensores habilitados por radio no cognitivo para la conservación de energía junto con radio cognitiva. sensores inalámbricos habilitados.

Limitaciones: El despliegue del dispositivo especial propuesto para sensores inalámbricos cognitivos habilitados para radio es complicado y requiere hardware especial con mejores nodos de sensores cognitivos alimentados por batería.

Palabras clave: CR-WSN, sensores cognitivos habilitados para radio, eficiencia energética, conservación de energía.

\section{Resumo}

Introdução: este artigo é o produto da pesquisa "Análise e previsão do espectro com base na aprendizagem em redes cognitivas de sensores de rádio", desenvolvida na Universidade de Sejong no ano de 2019.

Problema: a maioria dos esquemas de clustering para redes de sensores de rádio sem fio cognitivos distribuídos considera sensores sem fio homogêneos habilitados para rádio. Muitos esquemas de agregação para essas redes de sensores sem fio cognitivos homogêneos habilitados para rádio desperdiçam recursos e sofrem de ineficiência energética devido a sobrecarga desnecessária.

Objetivo: 0 objetivo da pesquisa é propor um esquema de agrupamento de nós que economize energia e prolongue a vida útil da rede.

Metodologia: Uma rede heterogênea de sensores sem fio cognitivos habilitados para rádio, nos quais apenas alguns nós possuem um módulo de rádio cognitivo e os outros nós são nós sensores normais. Juntamente com o custo do hardware, o esquema proposto é eficiente no consumo de energia.

Resultados: Simulamos o esquema proposto e o comparamos com redes de sensores sem fio cognitivos homogêneos habilitados por rádio. Os resultados mostram que o esquema proposto é eficiente em termos de consumo de energia.

Conclusão: 0 esquema de agrupamento de nós proposto funciona melhor em termos de conservação de energia e particionamento de rede.

Originalidade: Existem esquemas heterogêneos de agrupamento de nós na literatura para detecção cooperativa de espectro e eficiência energética, mas, tanto quanto sabemos, não há estudos que proponham um agrupamento de sensores não cognitivos habilitados por rádio para conservação de energia, juntamente com rádio cognitivo. sensores sem fio ativados.

Limitações: A implantação do dispositivo especial proposto para sensores cognitivos sem fio habilitados para rádio é complicada e requer hardware especial com melhores nós de sensores cognitivos alimentados por bateria.

Palavras-chave: CR-WSN, sensores cognitivos habilitados por rádio, eficiência energética, conservação de energia.

\section{INTRODUCTION}

"Cognitive radio-enabled wireless sensor networks" (CR-WSN) are a new variation of sensor network that accommodate sensors with cognitive radio (CR) modules. Many researchers reported in the literature that CR-WSN may solve future virtual spectrum 
scarcity issues. Although there are many research articles published in this domain, there is no real-world readily available application or deployment [1]. In fact, spectrum scarcity issues are a bottleneck in the development of future communication systems. Most of the electromagnetic spectrum bands that are useful for radio communications are already allocated. Some free bands available for public use, called ISM bands, are crowded, because venders developed technologies and devices for those bands. This spectrum scarcity issue can be mitigated technically without need for much modification to the current spectrum policy.

Wireless sensors are tiny energy constrained devices. Prolonging an entire wireless sensor network's lifetime is significantly important, especially in multihop wireless sensor networks. Several strategies are reported in the literature regarding the prolongation of WSN lifetime. Clustering nodes is one of the techniques used to conserve energy in wireless sensor networks that ultimately enhances a network's lifetime. Clustering involves forming logical groups of sensors for better resource utilization in ad hoc networks. Many CR-WSNs reported in the literature inherited similar techniques of clustering in CR-WSNs. They mostly considered wireless networks of homogeneous CR sensor nodes. However, if all the nodes in the network have CR modules, it increases deployment costs. Therefore, in this work we propose a clustering algorithm where only a few nodes have CR capabilities and all other nodes are general WS nodes without a CR module. We evaluate energy consumption from different elevations and compare them with existing algorithms.

Clustering allocates a network-wide spectrum sensing workload in CR-WSNs. This distributes the sensing issue, which is very important in CR-WSNs, into small local groups. The cognitive radio-enabled sensor nodes contribute to a sensing spectrum that helps collect spectrum information in a particular geographical location. Greater knowledge about the available white spaces mitigates interference with incumbent license holders, also called Primary Spectrum Users or PUs.

Clustering is pursued in cognitive radio-enabled-WSNs with the following objectives [2]-[6]:

(a) to gather local spectrum information,

(b) to allocate resources based on spectrum availability,

(c) mitigating interference between incumbent users and opportunistic spectrum users, also called cognitive users, or secondary users or SUs,

(d) to secure rights of the incumbent users on the channels,

(e) to reduce costs by deploying fewer CR-enabled sensors,

(f) to increase the scalability of the network, 
(g) to enable energy efficiency,

(h) to decrease communication costs, and

(i) to improve data aggregation efficiency.

The rest of the paper is organized as follows. In Section 2, works related to clustering in CR-WSNs are surveyed. The proposed node clustering scheme is described in Section 3. Simulation and comparison with existing algorithms are described in Section 4. Finally, Section 5 discusses the outcomes and recommendations for further work.

\section{RELATED WORKS}

An optimal long-haul transmit power solution is proposed based on the Lambert W function, where clusters are formed by deciding on the cluster heads in [7]. A spectrum-aware node clustering is presented in [8]; the optimal number of clusters for energy conservation was derived. Authors proposed group-wise constrained node clustering to minimize intra-cluster distance under spectrum-aware constraints. An event driven node clustering is proposed in [9]. In this scheme, cluster-heads were selected according to the number of nodes, availability of channels and the sink distance. A state of the art survey on node clustering in CR-WSNs is published by Joshi [10].

Qu et al. [11] proposed a spectrum sensing scheme based on clustering. In this work, CR-WS nodes are grouped in different sets. Based on the similarity in sensing results, authors in this work proposed an objective function. This function identifies the optimal cluster number. Their improved hierarchical clustering algorithm provides optimal cluster numbers, maximizing the objective function. However, their work does not avail details such as cluster formation and cluster head selection. Therefore, there was no comparative analysis between the proposed model and the existing models/algorithms.

A node clustering scheme for cooperative spectrum sensing was proposed by Rauniyar and Shin [12]. This scheme shows that during sensing, a pair of nodes in a group can alternate between sleep and wake modes. Shah et al. [8] proposed a cluster-based routing protocol called spectrum aware cluster-based energy-efficient multimedia (SCEEM). In SCEEM, incumbent users form a cluster based on the number of available common idle channels.

Cuervo and Lara [13] aimed to improve response times during surveillance by collecting photos and videos as immediate external evidence but the work is based on 
the Colombian territory. Triana et al. [14] resolved the issue in searching for configurations in network devices, which has proven to be a complex and repetitive task due to the wide variety of existing configurations.

Joshi and Kim [15] provided a comprehensive study of the contribution of node clustering in cognitive radio-enabled wireless sensor networks. The paper clearly outlines the purposes, necessities, and benefits of node clustering. However, they presented their work without considering the cost, size, and energy requirements. Srividhya and Shankar [16] proposed a node clustering scheme that is based on distance by using the multi-hop communication approach. Their analysis results show the improved network lifetime using a clustering and routing algorithm. Again, they have not considered the node clustering process with essential parameters such as spectrum availability and cluster head selection, among others. The performance study in [17] shows that the clustering process results in notable energy savings, thus enhancing the overall network lifespan. It also decreases (a) the clustering overhead as well as (2) the average distance between cluster heads and their members.

Eletreby et al. [18] discuss the clustering of cognitive radio sensor nodes in a dynamic frequency environment. They introduced cognitive LEACH (CogLEACH), which is a spectrum-aware extension. Their results show that the CogLEACH has higher throughput and lifetime. Kumar and Singh [19], in their work published in 2018, have compared the cognitive radio network (CRN) with the conventional mobile ad hoc network. The comparison was based on node mobility and dynamic channel availability.

There are heterogeneous clustering schemes in the literature for cooperative spectrum sensing and energy efficiency [2], [16], [20], [21], but to the best of our knowledge, there is no study as we proposed in the following section. Aforementioned works reported in the literature consider irreplaceable battery powered homogeneous nodes in the CR-WSNs. However, intuitively, not all nodes require cognitive radio modules; it is expensive and battery consuming. Along with other advantages of heterogeneity in WSNs, deploying special CHs with CR modules and other normal nodes can be an energy efficient and inexpensive solution. This is the motivation for proposing heterogenous CR-WSNs.

\section{METHODOLOGY}

As described in the Introduction, conventional node clustering in CR-WSNs considers homogeneous CR-WS nodes. However, we consider heterogenous CR-WS nodes, i.e., normal sensor nodes that are readily available for wireless sensor networks (WSN) with some special sensor nodes with CR modules embedded on those. These special 
nodes with a $\mathrm{CR}$ module are only eligible for the cluster head $(\mathrm{CH})$. We assume that there are certain numbers of such nodes with CR modules distributed uniformly in the networks. Cluster head selection is performed as in Low-Energy Adaptive Clustering Hierarchies (LEACH) [22]. Nodes without CR modules do not participate in the cluster head selection. Figure 1 shows the CR-WSNs including a Cluster head with CR module and normal sensor nodes, i.e. nodes without sensors.

Cluster heads broadcast an announcement to join the cluster to CR-WS nodes. After receiving the cluster head's announcement, the CR-WS node calculates the cluster head's requirements based on available energy and distance $(\bar{\delta})$ to the cluster head. Distance to the cluster head is calculated based on the strength of the signal, i.e. Received Signal Strength Indicator (RSSI), as in (1).

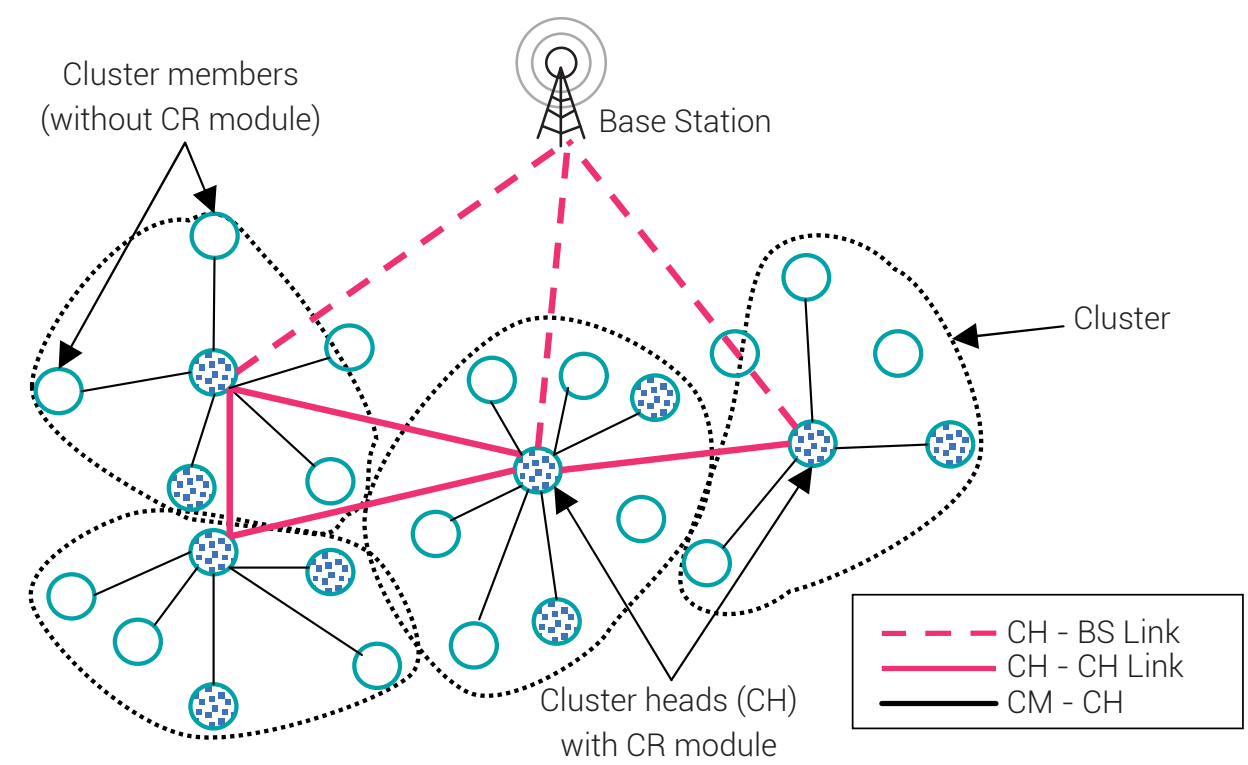

Figure 1. Proposed CR-WSNs with only cluster heads have CR modules.

Source: own work

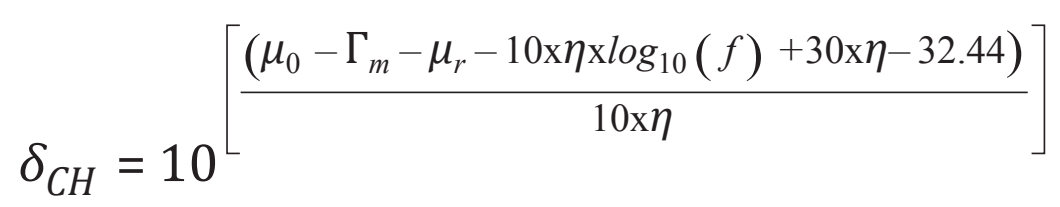

where, $\eta$ is the exponent of path-loss that ranges from 2.7 to $4.3, \Gamma_{m}$ is the fade margin, $\mu_{0}$ is the signal power $(\mathrm{dBm})$ at zero distance, $\mu_{r}$ is the signal power $(\mathrm{dBm})$ at distance $\delta$ and $f$ is the signal frequency in $\mathrm{MHz}$. 
We assume that the channel selection algorithm runs in the centralized spectrum server as shown in Figure 2. The spectrum server allocates channels, as in 802.22 regional area network [23]. Available channel information is sent by the cluster heads by sensing the spectrum of the server. The channel information is sent through a common channel. This channel is called a common control channel (CCC) and is dedicated to only control packets common to entire cluster heads in the network. Non$\mathrm{CH}$ nodes cannot use the common control channel. For simplicity, we used Carrier Sense Multiple Access with Collision Avoidance as a channel access method for the CCC. All cluster heads are equipped with multiple antennas, one for the CCC and another for data channels, where nodes can send and receive data packets. All cluster heads synchronize similar to 802.11 DCF's timing Synchronization Function (TSF).

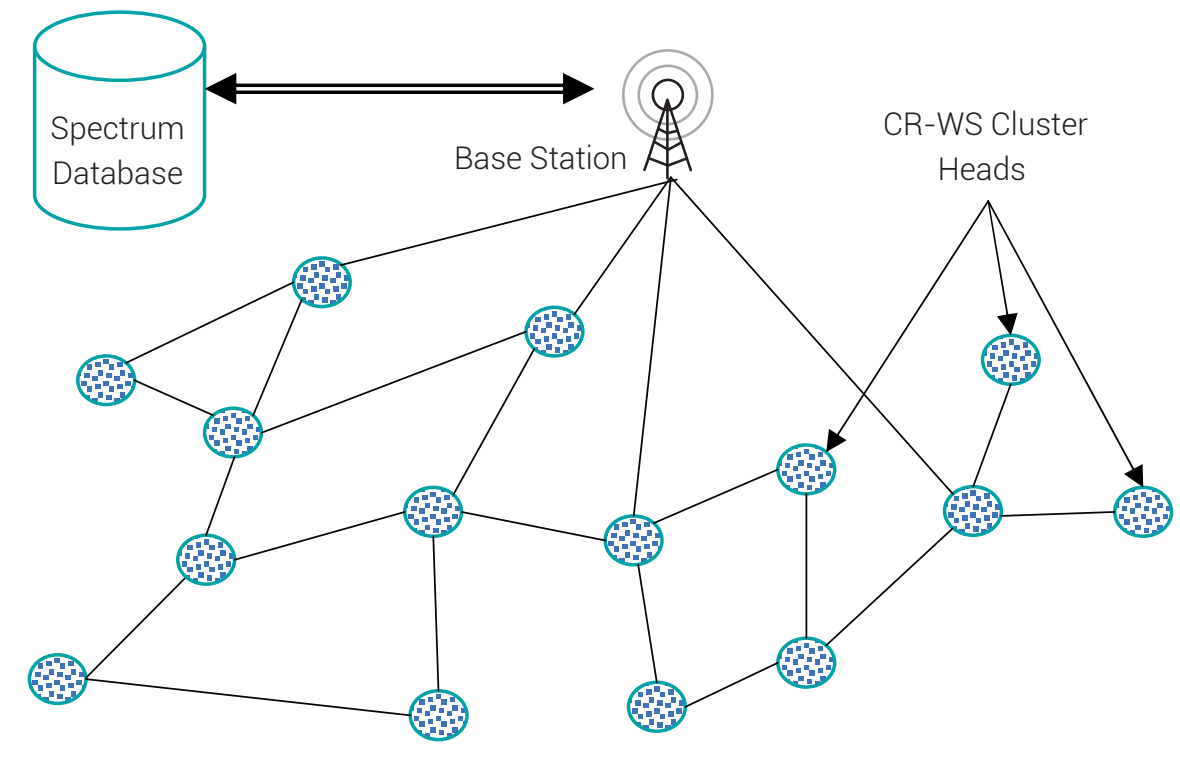

Figure 2. Cluster heads connected with base station and centralized spectrum database. Source: own work

In this work, we use a simplified form of the radio hardware energy dissipation model as described in [9]. We assume that $\mathrm{N}$ number of nodes are distributed in a $M \times M$ open space and there are $\mathrm{k}$ number of clusters. Based on the distance between transmitter and receiver, we use the free-space model, i.e., $\delta^{2}$ power loss model, and the multi-path fading channel model, i.e., $\delta^{4}$ power loss model. The cost of energy for a 1-bit packet transmission over $d$ distance by a cognitive radio-enabled node is given as follows. 


\section{Basic energy consumption model}

Here we describe the basic energy consumption model for a cognitive radio-enabled node. Let $n$ be the CR-WS nodes that are uniformly distributed in an area $A$ with $k$ clusters. Therefore, there are $\frac{n}{k}$ nodes in one cluster on average. In each cluster, there is a cluster head and $\left(\frac{n}{k}-1\right)$ cluster members. Multiple cluster head deployment is possible for backup cluster heads. Even if multiple cluster heads are deployed for backup, only one node acts as a cluster head at a time.

For the energy consumption of a member node in the cluster $\left(E_{C M}\right)$, let's denote the member node as $\mathrm{CM}$. With a transmission of $\beta$ bits, $E_{C M}$ can be calculated as follows:

$$
E_{C M}=\beta \times E_{\text {elec }}+E_{\text {amp }}(\beta, \delta)+E_{C M C R}
$$

where $E_{\text {elec }}$ is the energy expended in electronic circuitry to transmit or receive the signal, and $E_{a m p}(\beta, \delta)$ is the energy consumed by the amplifier for transmitting $\beta$ bits of data over distance $\delta$. $E_{C M C R}$ is the energy consumption for cognitive activities and can be computed as

$$
E_{C M C R}=E_{l c c}+E_{c c}+E_{s w}+E_{c r}
$$

where $E_{l c c}$ is the energy dissipated by the transceiver when listening on the CCC, $E_{c c}$ is the energy dissipated by the transceiver for channel negotiation in CCC, $E_{s w}$ is the energy dissipated for mandatory channel switching within the incumbent users' pre-specified tolerable time, $E_{c r}$ is the energy dissipated due to other cognitive activities such as channel indexing, PUs' arrival prediction, common channel selection, etc.

The energy consumption of a cluster head for data reception, data aggregation and transmission is:

$$
E_{C H}=\left(\frac{n}{k}-1\right) \cdot \beta \times E_{\text {elec }}+\frac{n}{k} \times \beta \times E_{D A}+E_{T X}(\beta, \delta)+E_{c r}
$$

where $E_{D A}$ is the energy consumed for data aggregation and $E_{T X}(\beta, \delta)$ is the energy consumed to transmit $\beta$ bits at distance $\delta$. $\mathrm{E}_{\mathrm{TX}}(\beta, \delta)$ can be estimated as 


$$
E_{T X}(\beta, \delta)=\left\{\begin{array}{r}
\beta \times E_{\text {elec }}+\beta \times E_{\text {amp }}^{\prime} \times \delta^{2} \\
\text { if } \delta \leq \delta_{0} \\
\beta \times E_{\text {elec }}+\beta \times E_{\text {amp }}^{\prime \prime} \times \delta^{4} \\
\text { if } \delta \geq \delta_{0}
\end{array}\right.
$$

where $E_{a m p}^{\prime}$ and $E_{\text {amp }}^{\prime \prime}$ are the energy consumed in the amplifier when $\delta \leq \delta_{0}$ and $\delta \leq \delta_{0}$.

Total energy consumed in each cluster is given by

$$
E_{\text {cluster }}=E_{C H}+\left(\frac{n}{k}-1\right) \times E_{C M}
$$

Now, we check our node clustering scheme and validate the simulation results.

\section{SIMULATION RESULTS}

We simulated and compared the simulation results. We used the $100 \times 100$ square area, with 100 number of total nodes. We assigned $E_{\text {elec }}$ as $50 \mathrm{~nJ}$ per bit, $\varepsilon_{f s}$ is $10 \mathrm{pJ} /$ $\left(\mathrm{bit} / \mathrm{m}^{2}\right)$ and $\varepsilon_{\mathrm{mp}}$ is $0.011 \mathrm{pJ} /\left(\mathrm{bit} / \mathrm{m}^{4}\right)$. The distance threshold $a$ is $80 \mathrm{~m}$ and the node initial energy is 150J. In the proposed scheme, the initial energy of the nodes with CR module is $450 \mathrm{~J}$.

Figure 2 shows the residual energy of average nodes while using the conventional 'all CR-WS nodes with CR module' and our scheme, i.e. heterogeneous sensors. The results show that the network lifetime is prolonged if we use only a few cluster heads with CR modules. The reason for this energy conservation is that only cluster heads participate in CR related tasks, such as channel sensing and channel switching to CCC for the sensing period, among others.

Figure 3 shows the residual energy of average nodes while using the conventional 'all CR-WS nodes with CR module' and our scheme, i.e. heterogeneous sensors. The results show that for the first 100 seconds, the depletion rate is similar. However, after that, the conventional method consumes more energy with significant difference. It shows that the network lifetime can be prolonged if we use only a few cluster heads with CR modules. The reason for this energy conservation is that only cluster heads participate in CR related tasks, such as channel sensing and channel switching to CCC for the sensing period, among others. 


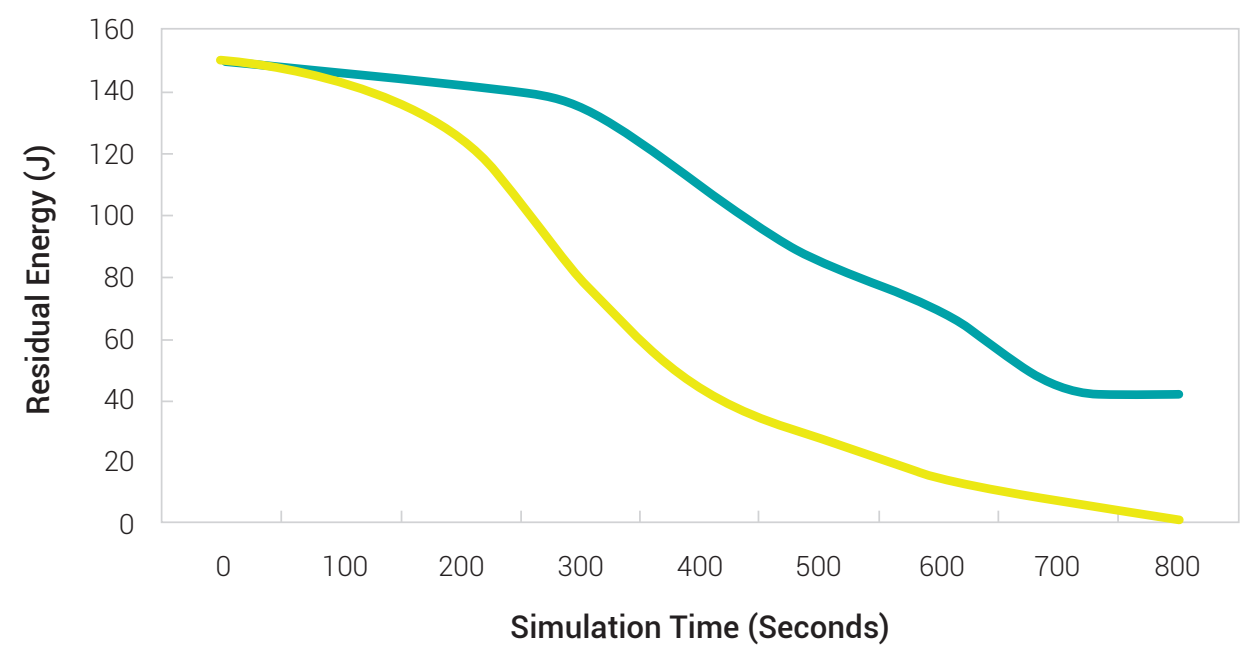

Homogeneous CR-WS

Conventional all CR-WS

Figure 3. Comparison of Energy consumption of heterogeneous CR-WSNs with the proposed scheme.

Source: own work

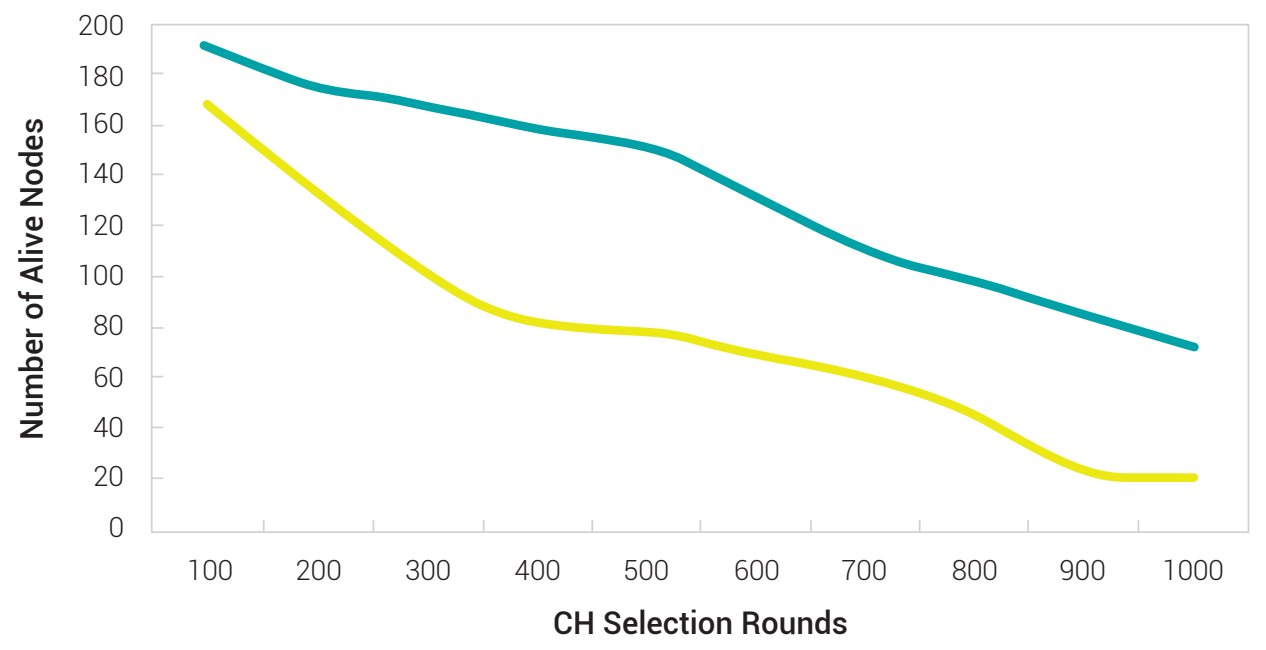

Figure 4. Comparison of total number of alive nodes in cluster head selection rounds. Source: own work

Figure 4 shows the comparison of total number of alive nodes in cluster head selection rounds. It shows that the number of alive nodes is comparatively high for the first 500 rounds in the proposed homogeneous CR-WSNs. However, it decreases 
significantly in the conventional all CR-WSNs. The reason why more nodes are alive in our scheme is similar that described in Figure 3. In conventional schemes, $\mathrm{CH}$ responsibilities are shared among all the nodes, but in the proposed scheme, CR related task are done by the special nodes with CR modules. Therefore, the number of alive nodes is higher in the homogeneous CR-WSNs scheme.

\section{CONCLUSION}

This is a preliminary work on node clustering for a heterogeneous CR-WSN design. In this work we proposed a node clustering scheme for heterogeneous CR-WSNs, where only nodes that participate in the role of cluster heads have a CR module. The simulation results show that the proposed sensor node clustering scheme performs better in terms of network energy conservation and network partition. The results from the simulation show that this scheme can be an inexpensive and viable solution for real-world CR-WSNs, because a large deployment of expensive sensors with CR modules is not always feasible and against the norms of the cognitive radio concept. As there is no such heterogeneous CR-WSNs reported in the literature, a comparison with such schemes is now our future works.

\section{REFERENCES}

[1] G. P. Joshi, S. Y. Nam, and S. W. Kim, "Cognitive radio wireless sensor networks: Applications, challenges and research trends," Sensors (Switzerland), vol. 13, no. 9, pp. 11196-11228, 2013. [Online]. doi: 10.3390/s130911196.

[2] S. Salim, S. Moh, D. Choi, and I. Chung, "An Energy-Efficient and Compact Clustering Scheme with Temporary Support Nodes for Cognitive Radio Sensor Networks," Sensors, vol. 14, no. 8 , pp. 14634-14653, Aug. 2014. [Online]. doi: 10.3390/s140814634.

[3] G. P. Joshi and S. W. Kim, "A survey on node clustering in cognitive radio wireless sensor networks," Sensors (Switzerland), vol. 16, no. 9, pp. 1465-1465, 2016. [Online]. doi: 10.3390/ s16091465.

[4] S. Wang, H. Liu, and K. Liu, "An Improved Clustering Cooperative Spectrum Sensing Algorithm Based on Modified Double-Threshold Energy Detection and Its Optimization in Cognitive Wireless Sensor Networks," International Journal of Distributed Sensor Networks, vol. 11, no. 10, pp. 1-7, Oct. 2015. [Online]. doi: 10.1155/2015/136948. 
[5] B. Jan, H. Farman, H. Javed, B. Montrucchio, M. Khan, and S. Ali, "Energy Efficient Hierarchical Clustering Approaches in Wireless Sensor Networks: A Survey," Wireless Communications and Mobile Computing, vol. 2017, no. 6457942, pp. 1-14, Oct. 2017. [Online]. doi: 10.1155/2017/6457942.

[6] Y. Yang, L. Dai, J. Li, S. Mumtaz, and J. Rodriguez, "Optimal spectrum access and power control of secondary users in cognitive radio networks," EURASIP Journal on Wireless Communications and Networking, vol. 2017, no. 1, pp. 98-98, May 2017. [Online]. doi: 10.1186/ s13638-017-0876-5.

[7] D. Wu, Y. Cai, L. Zhou, and J. Wang, "A cooperative communication scheme based on coalition formation game in clustered wireless sensor networks," IEEE Transactions on wireless communications, vol. 11, no. 3, pp. 1190-1200, 2012.

[8] H. Zhang, Z. Zhang, H. Dai, R. Yin, and X. Chen, "Distributed spectrum-aware clustering in cognitive radio sensor networks," in IEEE Global Telecommunications Conference-GLOBECOM 2011, 2011, pp. 1-6.

[9] M. Ozger and O. B. Akan, "Event-driven spectrum-aware clustering in cognitive radio sensor networks," in IEEE INFOCOM, Turin, Italy, 2013, pp. 1483-1491. [Online]. doi: 10.1109/ INFCOM.2013.6566943.

[10] G. P. Joshi, "Clustering in Cognitive Radio-based Wireless Sensor Networks," in 2016 International Conference on Advanced Computing, Communications and Information Science, Cebu, Philippines., May 2016, vol. 1, pp. 99-99, Accessed: Apr. 22, 2020. [Online]. Available: http://kasdba.org/icacci2016/proceedings/ICACCI2016_Proceedings.pdf.

[11] Z. Qu, Y. Xu, and S. Yin, "A novel clustering-based spectrum sensing in cognitive radio wireless sensor networks," in IEEE 3rd International Conference on Cloud Computing and Intelligence Systems, Shenzhen, China, 2014, pp. 695-699.

[12] A. Rauniyar and S. Y. Shin, "A Novel Energy-Efficient Clustering Based Cooperative Spectrum Sensing for Cognitive Radio Sensor Networks," International Journal of Distributed Sensor Networks, vol. 11, no. 6, pp. 1-8, Jun. 2015. [Online]. doi: 10.1155/2015/198456.

[13] M. A. S. Cuervo and J. A. M. Lara, "Prototipo de plataforma para vigilancia de inmuebles rurales usando computación en la nube y supervisión con drones," Ingeniería Solidaria, vol. 14, no. 24, pp. 3-17, Jan. 2018. [Online]. doi: 10.16925/in.v14i24.2160. 
[14] D. F. G. Triana, C. E. M. Marín, and P. A. G. García, "Lenguaje de dominio especifico para configuración de dispositivos de redes," Ingeniería Solidaria, vol. 12, no. 20, pp. 83-94, Oct. 2016. [Online]. doi: 10.16925/in.v19i20.1417.

[15] G. Joshi and S. Kim, "A Survey on Node Clustering in Cognitive Radio Wireless Sensor Networks," Sensors, vol. 16, no. 9, pp. 1465-1465, Sep. 2016. [Online]. doi: 10.3390/s16091465.

[16] V. Srividhya and T. Shankar, "Energy proficient clustering technique for lifetime enhancement of cognitive radio-based heterogeneous wireless sensor network," International Journal of Distributed Sensor Networks, vol. 14, no. 3, p. 1550147718767598, Mar. 2018. [Online]. doi: 10.1177/1550147718767598.

[17] S. Salim, S. Moh, D. Choi, and I. Chung, "An energy-efficient and compact clustering scheme with temporary support nodes for cognitive radio sensor networks," Sensors (Switzerland), vol. 14, no. 8, pp. 14634-14653, Aug. 2014. [Online]. doi: 10.3390/s140814634.

[18] R. M. Eletreby, H. M. Elsayed, and M. M. Khairy, "CogLEACH: A spectrum aware clustering protocol for cognitive radio sensor networks," in 2014 9th International Conference on Cognitive Radio Oriented Wireless Networks and Communications (CROWNCOM), Jun. 2014, pp. 179-184. [Online]. doi: 10.4108/icst.crowncom.2014.255370.

[19] S. Kumar and A. K. Singh, "A localized algorithm for clustering in cognitive radio networks," Journal of King Saud University - Computer and Information Sciences, vol. In press, pp. 1-8, Apr. 2018. [Online]. doi: 10.1016/j.jksuci.2018.04.004.

[20] D. Zhang et al., "Energy-Harvesting-Aided Spectrum Sensing and Data Transmission in Heterogeneous Cognitive Radio Sensor Network," IEEE Transactions on Vehicular Technology, vol. 66, no. 1, pp. 831-843, Jan. 2017. [Online]. doi: 10.1109/TVT.2016.2551721.

[21] G. A. Shah, F. Alagoz, E. A. Fadel, and O. B. Akan, "A Spectrum-Aware Clustering for Efficient Multimedia Routing in Cognitive Radio Sensor Networks," IEEE Transactions on Vehicular Technology, vol. 63, no. 7, pp. 3369-3380, Sep. 2014. [Online]. doi: 10.1109/TVT.2014.2300141.

[22] M. J. Handy, M. Haase, and D. Timmermann, "Low energy adaptive clustering hierarchy with deterministic cluster-head selection," in 2002 4th International Workshop on Mobile and Wireless Communications Network, MWCN 2002, 2002, pp. 368-372. [Online]. doi: 10.1109/ MWCN.2002.1045790.

[23] C. Cordeiro, K. Challapali, D. Birru, and S. Shankar, "IEEE 802.22: An Introduction to the First Wireless Standard based on Cognitive Radios," vol. 1, no. 1, pp. 38-47, 2006. 